\title{
Escenas metropolitanas
}

\author{
Valeria Bergalli Cozzi \\ Universitat de Batcelona. Facultat de Geografia i Història \\ Baldiri i Reixach, s/n. 08034 Barcelona. Spain
}

\section{Resumen}

En la ciudad industrial el conflicto social resultaba más visible que en el actual modelo urbano. En éste, existen una serie de obstáculos para que las autorrepresentaciones de los individuos se articuten de manera colectiva y solidaria. El proceso de disolución de las pertenencias vinculadas al modelo de ciudad industrial permite que otras asuman - en el nuevo contexto- un protagonismo hasta ahora inaudito. La figura del uinmigrante" se convierte en reveladora de la naturaleza de las pertenencias emergentes al tiempo que pone a prueba su capacidad integradora.

Palabras clave: ciudad global, intervención urbanística, procesos migratorios, imaginario urbano.

\section{Abstract. Building difference in the city}

In the industrial ciry, social conflict was more vistble than in the present urban model. In the latter, there are some obstacles in order for the self-representations of the individuals to be articulated in a collective and solidary way. Dissolution of the belongings related to the industrial city, makes possible that other, till recently not quite important belongings, become significant in the new context. The so-called «immigtant» reveals the nature of the emergent belongings and challenges their integrating capacity.

Key words: global city, urban intervention, migration processes, urban imaginaty.

La ciudad ha sido considerada el lugar en el cual se producen los cambios y las transformaciones que afectan a nuestras sociedades, así como el espacio privilegiado de configuración y manifestación del conflicto social y de las identidades de los sujetos de ese conflicto. La modernidad supuso para el espacio urbano la visibilidad de ese conflicto y de sus ámbitos de localización, entre los cuales la fábrica ocupaba un lugar central organizando el espacio urbano en función de la misma y según la relación que los habitantes de la ciudad mantuvieran con ella, puesto que dicha relación resultaba determinante para el establecimiento residencial de la gente. 
Sin embargo, el modelo de ciudad con el que hay que enfrentarse en este fin de siglo resulta algo diferente. La pérdida de centralidad de la producción industrial a favor de otros sectores abiertos por el proceso de innovación tecnológica, cuya expansión no puede asegurar la plena ocupación y que constituyen las partes de un sistema económico transnacional organizado en escala planetaria, convierte a los centros urbanos en enclaves de dicho sistema, el cual, a su vez, se encuentra necesitado de otras relaciones sociales y además presenta nuevas exigencias en materia de ordenación del espacio. Es en esta nueva fase de configuración de la ciudad en la que emerge "el espacio de los flujos en substitución del espacio de los lugares" (Castells, 1989, 348). De hecho, la ciudad global (King, 1990; Sassen, 1991) es justamente aqueila cuya configuración y dinámica es decidida desde su exterior, en un ámbito transnacional del que ella, como apuntaba antes, es un enclave. Sin embargo, la substitución de la que habla Castells no es total, en la medida en que la gente sigue viviendo y experimentando la ciudad en lugares mientras es el poder quien gobierna a través de flujos (Castells, op. cit., 349). Este desgarramiento obliga a los investigadores de la realidad urbana a desplegar un doble -y complementariopunto de vista que recoja ambos niveles: la experiencia de los habitantes de las urbes y el sistema económico y político del cual éstas forman parte ${ }^{\ddagger}$.

El análisis de la realidad urbana no se limita, por lo tanto, a la planificación y su aplicación en proyectos concretos; antes bien, quizás esa realidad comience más allá de eillas, puesto que la ciudad no ha constituido jamás un artefacto que responda completamente a la programación. La citudad está abierta a múltiples, diversas interpretaciones en la medida en que existen muchas formas de vivirla y porque, bajo los discursos que la ideologizan, proliferan las astucias y las combinaciones de poderes sin identidad legible, sin lugares donde aprehenderlas, sin transparencia racional, sin posibilidades de ser gestionadas" (de Certeau, 1980, 177). Es allí, en la experiencia de los ciudadanos, terreno de sorpresas y paradojas, donde radica su más profunda riqueza. De esas astucias y de esas combinaciones de poderes podemos tener noticia sólo en determinados momentos a veces de forma del todo imprevisible, mientras que en otros las echamos en falta y las consideramos inexistentes e incluso imposibles.

La ciudad industrial, con sus lugares tradicionales de afianzamiento de las identidades colectivas que le eran propias, las del trabajo y las de la política

1. Sin embargo, no siempte es fácil distinguir un nivel del otro, como, por ejemplo, ponen de manifiesro algunos aurores que analizan la emergencia de espacios que no pueden definirse en términos identificatorios, relacionales o históricos; es decir, lugares que no son antropologicos en tanto que no simbolizan la identidad compartida de un grupo, ni la particular (con respecto a otros), ni la singular (del individuo o del grupo en cuanto no semejantes a orros). En definitiva, lugares en los cuales no hay rastros de la idea que de la relación con el territorio, con sus semejantes y con los tortos" se hacen sus habitantes (Auge, 1993, 57 y sig.). De aquí que se denomine a estos espacios no hugares, puesto que propician una "comunicación tan extraña que, a menudo, no pone en contacto al individuo más que con otra imagen de sí mismon (Augé, op. cit., 85). 
(Barcellona, 1990, 35) -identidades estructuradas a partir y en torno de la centralidad de la fábrica- es ya nada más que una presencia fantasmal a la cual ha dejado de ser útil aferrarse para explicarnos la metrópoli actual. La desaparición de esa ciudad, junto a la desertización de los lugares en los que era posible la emergencia de autorrepresentaciones grupales de carácter solidario, creadoras de vínculos de pertenencia, se encuentra ligada a un proceso de homologación (Barcellona, op. cit.) vinculado al desarrollo tecnológico, en cuyo marco acontecen las utransformaciones de las articulaciones del proceso productivo y reproductivo, de los instrumentos de dominio y de control social, de las figuras del trabajo y de sus formas de socialización" (Barcellona, op. cit., 43). Versiones de este panorama general pueden ser rastreadas con mayor o menor facilidad en puntos diferentes del globo, pero lo que parece fuera de dudas es que él resume las tendencias en torno a las cuales se está organizando la vida urbana de nuestro futuro más próximo.

Con relación a este panorama, retomando el desgarramiento apuntado por Castells y concentrándonos en la experiencia de la ciudad propia de la gente que vive en ella, algunas de las nuevas prácticas sociales características del nuevo modelo parecen emerger con rapidez. El consumo, conjunto de prácticas urbanas por excelencia, parece estar manifestando una función socializadora que, con anterioridad, era menos evidente (Raulin, 1987), al tiempo que determina los lenguajes y los itinerarios de los individuos. De hecho, en nuestras ciudades ya casi no existen espacios en los cuales no se deba pagar para transcurrir en ellos parte de nuestro tiempo y, a la inversa, tampoco se nos ocurren demasiadas actividades que no supongan un cierto desembolso de dinero. En la actualidad, se ha acentuado de forma vertiginosa la expansión de los procesos que transforman en mercancía incluso las necesidades de comunicación humana más directa, invadiendo aś́ las esferas de la solidaridad interpersonal (Cantaro, 1990,21 y sig.). La extensión del mercado en tanto mecanismo regulador, no sólo del orden económico sino también del social y del político, da cuenta de su vocación totalitaria, puesto que se propone como instancia que pretende satisfacer todas las necesidades (íbidem). Las prácticas, itinerarios y fantasías marcados por el consumo son fundamentalmente individuales, alejan la posibilidad de constituir una comunidad o una colectividad (Barcellona, op. cit., 35) y, al mismo tiempo, son reveladoras de una tendencia uniformizadora. Por otro lado, el proceso de segmentación y jerarquización social (según la edad, el sexo, el origen geográfico y étnico, el poder de negociación, etc.) favorece la fragmentación de las clases en grupos sociales que disponen de un poder económico y cultural cada vez más desigual (Solé y Miguélez, 1987). De esta forma, por lo que respecta a la producción de las representaciones del sí mismo en el contexto urbano finisecular, puede hablarse de un impedimento para que esas representaciones se articulen de manera colectiva y solidaria dando lugar a símbolos y lenguajes susceptibles de resultar vinculantes y movilizadores. En efecto, tal como se ha escrito con relación a la Londres de la década de los ochenta, los sectores que en otro tiempo se encontraban organizados de acuerdo a intereses comunes y cuya movilización política era expresión de su papel 
en la ciudad industrial, se han visto privados de su capacidad de cohesión para constituir, finalmente, "sólo un conjunto de minorías o un agregado de personas despojadas de cualquier efectivo denominador político común" (Hobsbawn, 1987, 50). La capacidad de estos grupos de "producir mayorías, políticamente hablandon (íbidem) es inexistente y la práctica de aludir a ellos como "nuevos movimientos sociales" no parece, por ese motivo, justificada (fbidem). Sin embargo, todo ello no supone que no se produzcan fenómenos de agregación con una base territorial cuyo rechazo frente a la penetración del nuevo modelo y de sus consecuencias en materia de ordenación del espacio, puede hacerse visible si las circunstancias lo permiten. Por otro lado, el avance sucesivo, a lo largo del ciempo, de un modelo de ciudad en la cual los lugares donde la gente trabaja se encuentran cada vez más lejos de donde la gente vive, supone un corte drástico de las relaciones entre ambos ámbitos, de forma que la desmovilización se encuentra favorecida (Hobsbawn, op. cit., 48) a través de la desconexión entre las diferentes esferas de la vida cotidiana. A ello deben agregarse los efectos generados por la ausencia del pleno empleo, que permite una lectura de la distribución espacial de los grupos afectados en términos de una mayor tendencia hacia la producción de guetos. En éstos terminan por imponerse las intervenciones drásticas de recuperación (impulsadas por los poderes públicos y la empresa privada) con las que se fomenta la expulsión de los residentes. También puede recaer sobre ellos, sin embargo, la renuncia a cualquier tipo de reforma urbana, como parece ser el caso de algunas ciudades de los EE.UU., en las que se ha estado favoreciendo una polarización urbanística entre espacios radicalmente antagonistas (Davis, 1985, 113). De hecho, en ese país norteamericano parece estar resurgiendo el ordenamiento del espacio en cuanto medida destinada a contener una situación social explosiva, dividiendo las ciudades --es paradigmático el caso de Los Angeles- en áreas sociales no comunicadas entre sí con toda la intención de preservar a las más favorecidas de la ira difusa que emana de las que no lo son (Colombo, 1992, 19; Davis, 1993, 121 y sig.). Sin embargo, semejante polarización podría suponer no sólo una respuesta coyuntural a un problema local, sino el aferrarse a un modelo que, basándose en una "drástica división de mundos que se definen, con todo el peso de las barreras espaciales, como diferentes y hostiles, gobernados por reglas y derechos nunca tan abiertamente dispares [...], obstaculiza, aun antes de su concepcion, cualquier posible demanda de poder" (Colombo, op. cit., 20). Ello es así por cuanto la «asignación del poder real resulta establecida de una vez por todas por una ordenación del espacio que separa la ciudad de los dominantes de la de los dominados" ('bidem).

El debilitamiento de la identidad ligada a la clase social por parte de los sectores menos favorecidos, les supone la pérdida de un sentimiento de poder colectivo (Hobsbawn, op. cit., 49) y estimula una tendencia hacia la disgregación que, junto con las estrategias de estigmatización dirigidas a estos colectivos sobre los cuales recae el peso de la atribucion de "patologias sociales", les empuja a un proceso de marginación social creciente. Pensemos en la asociación que se establece entre estos grupos y los sectores urbanos en los que, se 
supone, residen: centros históricos y periferias, todos ellos presentados de manera que resulte exacerbado su grado de peligrosidad para los otros sectores de la ciudad, lo cual resulta funcional al despliegue de medidas de recuperación y control pero, sobre todo, a la fabricación de consenso y al fomento de la identificación de los ciudadanos con su urbe.

Con anterioridad se aludía a la visibilidad del conflicto en la ciudad industrial y a la capacidad, ligada a ese momento histórico, de organizarse frente a él. Ahora bien, visto el proceso de disolución de las antiguas pertenencias, emergen otras que no son completamente nuevas (como se verá más adelante), si bien asumen un protagonismo hasta ahora inaudito. Para ello, debe quedar claro que la ciudad global no se encuentra únicamente vinculada a centros financieros cuyo peso en la economía mundial es similar al de la ciudad en cuestión, sino también a otros centros cuya implicación en el sistema global se produce de forma subordinada y periférica.

La figura del inmigrante proveniente de esos centros y de sus ámbitos de influencia se convierte en reveladora de la naturaleza de las pertenencias emergentes, al tiempo que pone a prueba su capacidad integradora. De esas pertenencias hay una que parece sobresalir: la nacional. Con ella se alude a la pertenencia a una "comunidad política imaginada" (Anderson, 1983, 15), históricamente construida como comunidad identificadora de reacción ante el extranjero y el enemigo (Morin, 1991, 321). Ello implica que los proyectos nacionales (tanto los promovidos por los estados nacionales como por los movimientos nacionalistas de tipo reivindicativo) se basan en una dinámica de inclusión/exclusión que establece la pertenencia o la extranjería de las poblaciones en juego. Los ciudadanos de un estado - -sean éstos definidos así sobre la base de la herencia o de la voluntad - son considerados tales desde un punto de vista que privilegia la pertenencia étnico-nacional, y la citudadanía termina por confundirse con los límites trazados por esa pertenencia. A través del fenómeno de la inmigración ha sido posible descubrir la logica excluyente que subyace a esta concepción de la ciudadanía, prosiguiendo así un proceso de desvelamiento de esa lógica que ha ido poniendo al descubierto el sujeto que sirvio de modelo a dicha concepción -el hombre, adulto, propietario-y la exclusión -o sea, el ser sujetos privados de derechos- a la que se vieron abocados quienes no encajaban en semejante modelo. La renuncia a reconocer una paridad de derechos entre los extranjeros y los autóctonos es algo que se encuentra en las legisiaciones de todos los países del mundo, en la medida en que, quien más o quien menos, establecen limitaciones a la presencia de los primeros o procedimientos más o menos severos para su naturalización (Rusconi, $1989,28)$; de aquí que antes se hiciera referencia a la emergencia de pertenencias no completamente nuevas. De hecho, en nuestra concepción de la citidadanía se esconden hace ya tiempo algunos de los elementos que permiten la articulación de los mecanismos de inclusión/exclusión mencionados más arriba.

Pero volvamos a la ciudad. Ella también podría definirse como imaginada. En tanto que representación más o menos compartida por un conjunto de 
individuos, existe más altá de su carácter de espacio producido por un conjunto de factores de orden geográfico, histórico, económico, político y social. Y elia es también susceptible de producir pertenencia, como se podría demostrar si fuera éste el lugar donde profundizar en el análisis de algunos casos ilustrativos (rivalidades entre ciudades, protagonismo de la ciudad sobte la tegión en la que está emplazada, etc.). De hecho, existe la expresión "patriotismo de ciudad", que pone de manifiesto lo que aquí se sostiene. Como la pertenencia a la nación, también la pertenencia a la ciudad constituye una construcción social en la que intervienen múltiples factores entre los cuales destacan, quizás, un cierto uso del pasado vinculado a procesos de invención de la tradición (Hobsbawn y Ranger, 1988, 13 y sig.), cuya difusión en el marco metropolitano puede acontecer a través de vías equivalentes a aquéllas por las que se difunden los contenidos de la nación - las conmemoraciones, las grandes celebraciones - o a través de otras diferentes como, por ejemplo, la intervención urbanística. En un contexto de crisis urbana, dicho patriotismo puede resultar movilizador $\mathrm{y}$, no en vano, es estimulado desde el poder político ( $\mathrm{y}$ la empresa privada asociada a él) en la medida en que puede ser efectivo para la producción de consenso. De lo que se trata es de vehicular una representación de la ciudad de la que ese patriotismo se pueda nutrir y hegemonizar el imaginario urbano de sus habitantes. La estrategia no siempre tiene éxito, pero en algunos casos éste parece ser estrepitoso. El de Barcelona y su proceso de renovación urbana con ocasión de los Juegos Olímpicos del año 1992, podría ser un ejemplo. La repetida alusión a Barcelona como "metrópoli mediterránea», que subyacfa a las intervenciones urbanísticas que favorecían lo que se llamó el "reencuentro" de la ciudad con el mar, tenían como objetivo la producción de una identidad portuaria para la urbe. La recuperación, exclusivamente retóri$\mathrm{ca}$, de la condición de puerro de Barcelona, venía a ofrecer el soporte para un supuesto talante cosmopolita que revertiría como particular aportación barcelonesa a la llamada "Europa de las ciudades", donde el poder municipal quiere afirmar la presencia de la capital catalana (Bergalii, 1993, 33).

Lo que me interesa subrayar aquí es que estos procesos de construcción de identidades colectivas, basados en una lógica en la cual la construcción del sí mismo es un proceso de carácter interdependiente de la construcción del "otro", se producen en contextos históricamente determinados en los cuales los contenidos del sí mismo y del otro resultan fijados según las peculiaridades del momento, como también según las necesidades hegemónicas vinculadas a intereses de orden económico y/o político. Analizar el tipo de idea de ciudad - y sus posibles alternativas si éstas son susceptibles de ser aprehendidas - que en un lugar y momento determinados se pretende imponer, significa relacionarla con el proceso de construcción de las autorrepresentaciones de sus habitantes y del papel que, en ese contexto, tienen los "otros". En el caso de Barcelona, por ejemplo, este papel parece limitarse a cumplir una función de soporte que asegura simbólicamente la experiencia del cosmopolitismo antes mencionado. Revalidar la naturaleza portuaria de la ciudad supone reactualizar un imaginario exótico inscrito en el territorio (sobre todo en las zonas 
próximas al mar o que llevan a él, como la Rambia) que supuestamente posibilita entrar en contacto con el resto del mundo. Los inmigrantes de los países periféricos resultan incorporados a ese universo (¿pueden ser considerados los nuevos marineros?) en la medida en que proveen a los autóctonos de una presencia contra la cual afirmar la propia identidad. Puede verse, entonces, que caer en la tentación de considerar positivamente la presencia de ese universo exótico, como garantía de la expresión de múltiples autorrepresentaciones con vistas al advenimiento de la llamada sociedad multicultural, parece poco aconsejable. Como se sabe, lo exótico no tiene unos orígenes inocentes, ya que se encuentra relacionado a la producción de imágenes de la mirada europea y de su histórica incapacidad para valorar la diferencia. Una mirada que, por lo general, se posaba sobre el mundo para establecer con él, exclusivamente, un inquietante monólogo.

\section{Bibliografía}

ANDERSON, B. (1983). Imagined Communities. Reflections on the Origin and Spread of Nationalism. Londres: Verso.

AUGE, M. (1993). Los «no lugares». Espacios del anonimato. Una antropologia de la sobremodernidad. Barcelona: Gedisa Edirorial.

BARCELLONA, P. (1990). Il ritorno del legame sociale. Turin: Bollati Boringhieri.

BERGALLI, V. (1993). «Barcelona, Ramblas abajo. La ciudad, el mat y el extranjero". Archipielago, núm. 12, p. 29-34.

CASTELES, M. (1989). The Informational City: Information Technology, Economic Restructuring and the Urban-Regional Process. Oxford: Basil Blackwell.

CANTARO, A. (1990). La modernizzazione neoliberista. Le istituzioni e le regole del nuovo ordine. Milán: Franco Angeli.

CERTEAJ, M. de (1980). Linvention du quotidien. I. Ants de faire. París: Union Générale d'Editions.

COLOMBO, A. (1993). «I muri di Los Angeles. Un modello per if dominion, En AA.VV. Los Angeles. No Justice, No Peace. Roma: Manifestolibri.

DAVIS, M. (1985). "Urban Renaissance and the Spirit of Postmodernism". New Left Review, núm. 151, mayo-junio, p. 106-113.

- (1993). La cittá di quarzo. Indagine sul futuro a Los Angeles. Roma: Manifestolibri. Edición original: City of Quarz. Excavating the Future in Los Angeles. Nueva York: Vintage Books, 1992.

HOBSBAWN, E. (1987). "Labour in the Great City". New Left Review, núm. 166, noviembre-diciembre, p. 39-51.

HOBSBAWN, E.; RANGER, T. (1988). L'invent de la tradició. Vic: Eumo Edirorial.

KING, A. (1990). Global Cities. Post-Imperialism and the Internationalization of London. Londres: Routledge.

MORIN, E. (1991). "L'Etat-nation. En DelanNoI, G. y TAGUIEFF, P.A. (Dirs.), Théories du nationalisme. Nation, nationalité, ethnicité. Paris: Editions Kimé.

RAULIN, A. (1987). "Où s'approvisionne la culture?". En GUTWIRTH, J. y PETONNET, C. (Dits.). Chemins de la ville. Parfs: Editions du CTHS.

RUSCONI, G. E. (1989). "Questione etnica e cittadinanza». Democrazia e diritto, núm. 6, noviembre-diciembre, p. 23-41. Roma. 
SASSEN, S. (1991). The Global City: New York, London, Tokio, Princeton: Princeton University Press.

SOLE, C. y MrGUELEZ, F. (1987). Trabajo y crisis económica en Cataluña. Barcelona: PPU. 